\title{
Data Mining of Social Media - the Bridge between Traditional and Social CRM
}

\author{
Sohail Subhani, PhD \\ Professor of MIS \\ Business Administration Department \\ Winona State University \\ 175 Mark Street, Winona MN 55987, USA
}

\begin{abstract}
During the mid-1980's, the marketing focus shifted from the traditional marketing mix model of 4 P's to relationship marketing. Relationship marketing, an approach that develops strong connection with customers by promoting customer loyalty, interaction, and long-term engagement, is the philosophy behind customer relationship management (CRM). Traditional CRM programs of the mid-1980's facilitated one-way communication from the business to the customer. However, with the coming of the internet and social media in the 1990's, two-way communication between the business and the customers became the norm. Marketing focus once again shifted - from customer relationship management to customer engagement. Large amounts of unstructured social media data generated by customer business interactions require integration of data mining tools and social media into the CRM to unlock potential information.
\end{abstract}

Keywords: Data Mining, Social Media, Social CRM, Customer Relationship Management

\section{Introduction}

Customer relationship management (CRM) systems of the 1980s focused mainly on providing support for sales, marketing, analysis and data integration (Rapp, Trainor, and Agnihorti, 2010) and relied heavily on corporate databases and internal technologies that were specific to the organization and the CRM system. With the arrival of the internet in the 1990s, organizations were able to reach out to customers anytime, anywhere, but could not harness the full potential of the internet as they merely transferred their traditional marketing approaches to an online platform (Shah \& Murtaza 2005). As social media and Web 2.0 grew in popularity in early 2000, CRM got a new boost. Web 2.0 and new social media technologies, being collaborative, are well suited to social CRM as they contribute to relationship marketing (Hennig - Thurau et al., 2010). The notion of social CRM came about the same time as the advent of social networking platform and will continue to evolve with advancements in social media technologies. According to Greensberg (2010), social CRM provides mutually beneficial value to customers and organizations by facilitating collaborative interaction between them. It does not replace but builds on traditional CRM by including social functions, processes, and capabilities to promote communications between customers and businesses.

\section{The emergence of the CRM concept}

The conventional approach used by firms to influence consumers' purchase decisions was based on the marketing mix model of 4 P's - price, product, promotion, and place. The success of a product's purchase depended on a firm's ability to control these variables (4 P's) in an effective manner (Kotler, 1992). During the mid-1980s, there was a paradigm shift; the marketing focus moved away from the traditional marketing mix model of 4 Ps to relationship marketing (Gronroos, 1994). Relationship marketing is an approach designed to promote customer loyalty, interaction, and longterm engagement. Its purpose is to develop strong connections with customers by providing them with information related to their needs and promoting open communication (Jain,2005). It stresses more on customer retention and satisfaction rather than on short term goals like customer acquisition and individual sales. Relationship marketing is the philosophy behind customer relationship management. Thus, customer relationship management (CRM) is an approach to manage a company's interaction with current and potential customers to improving business relationships and customer retention to increase sales and profitability.

The idea of CRM gained broad acceptance in the late 1990s and was regarded as one of the most popular management tools. Improvements in computer technology, along with the emergence of internet technology, contributed to the growth of CRM (Madsen \& Johnson, 2016). However, the implementation of customer relationship management (CRM) initiatives has been disappointing, with many failures reported (Jayachandran et al.2005).

Many studies and viewpoints have sought to explain the high failure rate of CRM initiatives. The next section examines the main reasons suggested for CRM failure. 


\section{Some Reasons for CRM failure}

Organizations are committed to a successful implementation of CRM projects as it is a key to profitability in a competitive environment. Therefore, it is not surprising that a high failure rate of CRM projects prompted search into causes of its failure leading to valuable insights. Most of the proposed opinions and ideas link failure to poor integration of CRM systems with other information subsystems, lack of implementation strategy, and misconceived notion and misconception of customer relationship management.

Poor integration of CRM with other information subsystems is one of the factors contributing to the failure of CRM. The full potential of CRM is realized when it is integrated with other information subsystems, such as customer information management (CIM), and enterprise resource planning systems. By combining customer information management (CIM) with customer relationship management (CRM), organizations can control the necessary information resources and make effective decisions about customers and business activities (Chettayar, 2002). Integrating CRM with ERP and e-commerce application provides real power to CRM as it unlocks enterprise information (West, 2001).

Lack of implementation strategy and ineffective change management (Rigby, Reichheld \& Scheffter, 2002) is also cited as a significant cause of CRM failure. Organizations should evaluate, and if necessary, make appropriate changes to their organizational structures and business processes before embarking on to implement a CRM program. A welldefined customer and corporate strategy must be in place before implementing CRM. The purpose is to create a customer-centric organization where performance, compensation, and training are all restructured to meet customers' needs. A customer-centric organization will not only facilitate the implementation of customer acquisition and retention strategy but will also help plan for relationships, such as avoid building relationships with wrong customers and with customers not wanting to have affiliations.

Misconceived notions of CRM can also result in CRM failure as it creates unrealistic expectations. Many executives have assumed that CRM has to be technology intensive thinking that installing CRM software would solve all their problems, and when it failed to do so, they were disappointed. The notion that investment in CRM technology alone is sufficient to improve performance is misguided (Fan \& Ku, 2010). Successful CRM depends more on the strategy than on the amount spent on technology.

The misconception that CRM is the same as one-to-one marketing has also contributed to CRM failure. (Peppers, Rogers, \& Dorf, 1999). Gummesson (2010) attributes one-to-one focus on the shortcomings of CRM initiatives. Oneto-one marketing tries to identify the needs of individual customers and develop products or services to satisfy those individual needs. However, with the growth of the internet and innovations in information technology, it is now possible to identify and cater to the needs of individual customers, but it is not a prudent strategy. Blindly following the conventional wisdom of responding to the needs of individual customers may be dangerous (Thomke \& Hippel, 2002). It may also not be possible for organizations to develop a special relationship with every customer (Tinsley, 2002). Use of CRM to foster a one-to-one relationship with customers is also not a viable option as relationships typically involve more than two customers or companies, leading to a many-to-many perspective (Gummesson \& Mele, 2010).

The goals of CRM are to increase customer acquisition and retention, respond effectively to competition, and improve customer service. These goals were not always realized even with fully integrated and well implemented CRM systems. The arrival of social networking platform adds a new dimension of interactivity viewed by many as a key to the success of customer relationship management.

\section{Customer Relationship Management and Social Networking Platform}

Customer relationship management (CRM) is a strategy for managing an organization's relationships and interactions with current and potential customers to gain information about them. Companies use customer information to maximize customer lifetime value and to develop customized marketing activities (Schulz, Skiera, \& Wiesel, 2012).

Traditional CRM approach and technologies facilitated one-way communication from businesses to consumers, where the company proactively managed the customer relationship; customers were merely passive recipients of the message (Reinartz, Kraft, \& Hoyer, 2004). The inability of traditional CRM technologies to provide two-way communication between businesses and consumers severely constrained interactivity (Trainor 2012). This lack of interactivity is viewed as a major cause of customer relationship management (CRM) failure by many in the field.

However, the arrival of social media and social networking platform made real-time interactive communication between businesses and consumers easy and possible (Deighton and Kornfeld, 2009). Customers are now actively engaged in formulating the relationship. They have more information about competing products and can voice their opinions to a large number of users. It is also difficult for businesses to control the messages customers receive about 
their products (Schulz, Skiera, \& Wiesel, 2012). Thus, social media technology has empowered consumers by promoting real-time, two-way interactive communication (Labrecque et al., 2013).

\section{How Social Media is Shaping Customer Relationship Management}

Social media is defined as a group of Internet-based applications that allow the creation and exchange of user-generated content and are based on the concepts and technologies of Web 2.0 (Kaplan and Haenlin, 2010). Social media technologies include Facebook, Twitter, LinkedIn, blogs, wikis, YouTube (Kim and Koik 2012). Social media technologies are potent enablers to CRM. They have changed the way businesses, and customers interact with each other by facilitating real-time, two-way communication between them (Van Bruggen et al., 2010), resulting in increased customer engagement.

Social media, being digital with virtually zero marginal cost, allows distribution of digital products instantly without having to pass through traditional channels. Entries made in forums, blogs, and other digital media can be tracked by anyone, thus providing high visibility. Comments and reviews can be accessed at the time they are produced, allowing participants to share their experience in real time. They are often available indefinitely to potential customers for years to come. Ability afforded to consumers to reach and be reached from anywhere and anytime through their mobile devices makes social media ubiquitous. These features of social media will have far-reaching implications for customer relationship management (CRM).

\subsection{How Businesses Use Social Media}

Social media offers businesses different ways to reach customers, communicate with them, and monitor their communication and browsing behavior (Hennig-Thurau et al., 2010). Companies are using social media for meaningful engagement with their customers. Some are using it to advertise their products and services (Hansson, Wrangmo, \& Soilen, 2013). Others are using it to provide customer support and information about their products and services and to stay connected to their customers (Mitic \& Kapoulas, 2012).

\subsection{How Customers Use Social Media}

Customers are no longer passive recipients of a firm's marketing communication but are actively engaged in value creation (Baird and Parasnis, 2011). They use social media to participate in social networks to create, share, and communicate with one another and build relationships with other consumers. Through social media, customers share experiences with each other and access customer services (Brodie et al., 2013). They use new media to contribute to all phases of the value chain ranging from reviews on retail sites, to co-creation of products and services, like testing beta products and developing open-source software (Kumar et al.,2010).

\section{Traditional CRM versus Social CRM}

The goal of any CRM, traditional or social, is to increase sales and profitability through the acquisition of new customers, retention of profitable customers, and termination of non-profitable customers. Traditional CRM used old methods of communication with customers, such as phone calls, e-mails, and live meetings. Contact profile of each customer was included in the database along with the interaction history between the customer and the company. Traditional CRM aided one-way communication from business to customer. As a result, the relationship was mostly directed by the company. Traditional CRM approach viewed customers as individual decision makers who generated value for the company by purchasing its products or services (Matthouse et al., 2013). Customer's worth to the company was measured using customer lifetime value (CLV), which is the present value of profits generated by customers over their life of business with the organization (Kumar et al., 2010).

Social CRM employs social media to enable organizations to interact with their customers. It does not replace but enhances traditional CRM by promoting two-way communication between customers and businesses. With this empowerment of consumers to participate in and contribute to marketing communication, businesses are no longer able to control the communication process as before. The collaborative activities enabled by social media have made customer relationships about engaging rather than managing people (Greenberg, 2010). Social media has also played an essential role in viral marketing, which allows a message to be transmitted instantly to a large group of people expediting the positive or negative impact on a company's product (Kaplan and Haenlein, 2010).

Social CRM has facilitated the building of a consumer-centric approach to marketing communication, which ensures a viable long-term relationship (Finne and Gronroos, 2009). It has also enabled co-creation of value, an approach that promotes and encourages active participation of customers in the production of their value offerings using company provided resources (Payne and Frow, 2005). Co-creation of value is also a way of developing and maintaining beneficial customer relationships (Earnst, Hoyer, Kraft, and Krieger, 2011). 
For organizations to reap the benefits of social CRM, they must understand the challenges posed by this new paradigm. The next section examines some of those challenges.

\section{Challenges of Social CRM}

The convergence of social media with CRM facilitates customer engagement resulting in an improved and viable relationship. However, it is not clear how to enable customer engagement initiatives in organizations to create value (Bijmolt et al., 2018). This lack of clarity creates challenges for organizations that are looking to implement CRM. However, creating closed forums and relevant content to let customers form a community that solves real problems could encourage customer engagement. Personalizing customers' interactions with organizations using social media may also foster customer engagement.

Metrics relevant to social media that measure customer value include customer referral value (CRV), customer influence value (CIV), and customer knowledge value (Choudhry and Harrigan, 2014). Customer referral value (CRV) stems from the referral of new customers, whereas customer influence value (CIV) emphasizes the value of customers who share information and assist other customers. On the other hand, customer knowledge value (CKV) underscores the value of customers who possess expert knowledge. The social media metrics (CRV, CIV, and CKV) are in addition to customer lifetime value, which is an older measure of customer value used in traditional CRM and is calculated as the present value of profits generated by customers over their life of business with the organization. Customer lifetime value can be estimated from the customer's transactions with the organization. However, estimating customer value using social media metrics poses a challenge.

Information processes comprise of capturing, integrating, and accessing information. Social media adds complexity to information processes. Capturing information generated by social media is challenging as firms have to gather vast amounts of data from diverse sources, including Facebook, tweets, and text messages. Integrating information produced as a result of interaction on social media is equally challenging as it requires combining customer information from all interactions to create a single generalized view of the customer (Jayachandran et al., 2005). Accessing information means making information available in an operational and timely manner. The unstructured and qualitative nature of social data makes information access a complicated process.

To overcome the challenges and reap benefits of social CRM, data mining techniques should be integrated into social CRM.

\section{Data Mining in Social CRM}

Data mining uses sophisticated data search capabilities and statistical algorithms in examining large data sets to find patterns and correlations to predict outcomes and solve problems through data analysis. The goal of data mining is to find new information in a data set that is latent and not readily apparent. Data mining techniques are well suited to analyze big data. Social media is central to social CRM. With the growth of online social media providing a large amount of data, application of data mining techniques to social media can provide valuable insights, which could lead to improved implementation of CRM.

\subsection{Reasons for using Data Mining in Social Media}

Social data mining is the process of extracting patterns and forming conclusions about users from the user-generated content on social media. Use of data mining techniques to social media is on the rise. It is challenging to gain useful information from social media data without applying data mining technologies. Social media data have four characteristics that pose unique challenges. First, social media data are enormous. Without automated data mining techniques, analyzing social media data in any reasonable amount of time is impossible. Second, social media data sets can be noisy, such as spam blogs and frivolous tweets. Third, social media data sets are dynamic, characterized by frequent changes and updates over short intervals. For example, blogs and wikis are created continuously and modified. Social media allows considerable production of interactive data, such as microblogs posts, chat messages, and blog comments. Fourth, social media data is unstructured and comes in a variety of formats, such as e-mails, photos, videos, and phone messages. Finally, the advancement of the field of data mining relies on large data sets. Social media, being the source of extensive data, provides the venue for developing and testing new data mining techniques.

\subsection{Data Mining Techniques}

Data mining techniques are used to find hidden patterns in an extensive data set and use those patterns to predict the future and find unfamiliar data elements in a data set. Commonly used data mining techniques are: Association Rule Learning looks for events or attributes that are highly correlated with another event or attribute. It is used for discovering the relationship between items that exist with each other, such as in transaction data recorded via point-ofsale systems. 
Association has been used for promotional pricing, market basket analysis, and customer clustering. Classification assigns cases in a set of data to specific categories. The goal of classification is to accurately predict the target class for each case in the data. For example, a classification model could be used to identify loan applicants as low, medium, or high credit risks.

Clustering involves partitioning data or object into a set of meaningful sub-classes, called clusters. Objects in the same group are more similar to each other than to those in other groups. Clustering has been applied to market segmentation, social network analysis, and propensity to cross-sell.

Regression Analysis shows how the value of one dependent variable varies when independent variables are changed. It helps to uncover the exact relationship between two or more variables in a given data set. For example, it can be used to project the price of a house based on the size, age, number of rooms, and location. Visualization is the process of conveying information through images, graphs, and charts that can be quickly and easily absorbed by the viewer. It can be used in conjunction with other data mining tools to provide a clear understanding of the hidden patterns and relationships.

\subsection{Applications of Data Mining to Social Media}

There are two types of social media data. One type originates from social networking sites such as Facebook, and the other type is blogs. Through social networking sites, users can connect to other users and share news, pictures, videos, and favorite links. In a social networking site, group structure resembles a typical graph structure where users are represented as nodes, and their relationships are represented as links. Blogs are user published entries on the web, also known as posts, that cover a wide range of topics. Blogs are generally open to the public for viewing and making comments on the post. Without data mining tools, a small percentage of social media data could be effectively analyzed.

\subsubsection{Social Networking Sites Data}

The most common data mining applications associated with social networking sites are:

Group detection is a popular application of data mining of social networking sites like Facebook and LinkedIn. The aim is to find and identify groups based on various attributes. It is created by analyzing the structure of the network to find individuals that are similar in characteristics and associate more with each other than with other users. Establishing a group can provide valuable insights into the activities, goods, and services that are of interest to the group. It also provides information about the number of distinct groups. Clustering is a data mining technique used in group detection that determines which data elements in the data are similar to each other so as to form groups. For example, clustering can be used to form groups of low, moderate, and high credit risk from a set of attributes.

Group profiling is used for establishing what the group is about once a group is formed. It helps one understand social structures. A data mining technique used in group profiling is classification, which learns from the training data to build a model for categorizing new data into one of the distinct classes. For example, classification can be used to identify individuals as a low, moderate, or high credit risk based on pertinent attributes. Group profiling can be used to recommend new friends or new groups to a user. It can also facilitate the marketing of goods, services, and ideas to specific groups based on similarities.

\subsubsection{Blog Analysis}

The most common data mining applications associated with blogs are:

Blog classification -With numerous blogs available to choose from, the ability to automatically classify and organize blogs by topic helps in the blog search. Descriptive words or tags are used to classify blog posts automatically. The algorithm removes unnecessary text from the blog and then compares the remaining text to the tag database to assign the best tag to the blog (Yadav \& Kharade, 2016).

Identifying influential blogs -Influential blogs can affect the behavior of other bloggers. They can be used to propagate information about a product, service, or topic and therefore, can be a valuable source for referral of the new customers and points of influence. The influence of a blog is measured by a combination of four factors (Liu \& Agarwal, 2009): recognition, activity generation, novelty, and eloquence. Recognition is the number of other blogs referring to the blog post (in-links). Novelty is the number of blogs referred to by the blog post (out-link). Activity generation is the number of comments a blog post receives. Eloquence is the length of the blog post. These four elements are combined to generate a measure of blog influence.

Topic detection and change - Blog contents vary over time as new posts are added, opinions change, and blog sites are updated with new information and topics. Identifying popular topics and opinion leaders in the blogosphere can provide insights into prevalent views. An opinion leader is a blogger that publishes new ideas and is influential. 
A popular data mining technique used for identifying new topics and opinion leaders is Latent Dirichlet Allocation (Rygielski et al., 2002). Applying data mining techniques can also help detect trends and changes.

Sentiment analysis -People feelings (sentiments) about a topic are just as important as the topic itself. The purpose of the sentimental analysis is to find opinions, identify the sentiments expressed by them, and classify those sentiments according to their orientation (positive, negative, or neutral). It is used for analyzing social emotions and sentiments related to a product or event. Some common data mining techniques that have been used are support vector machines (SVM) and text mining (Yadav \& Kharade, 2016).

\section{Conclusion}

Businesses should integrate data mining with CRM to analyze large amounts of data captured over the years through various customer interactions. Integration of data mining with CRM allows businesses to use customer data and information effectively. Data mining of large amounts of customer information would reveal hidden patterns which otherwise could have been too time-consuming and complex to achieve. Implementation of a CRM program that incorporates data mining enables organizations to improve customer loyalty, increase the value of their customers, and attract the right customers.

Integrating data mining with CRM will resolve some of the challenges posed by social CRM. Group detection and group profiling of customers can provide deep insight into their activities, goods, and services that are of interest to them. A profound understanding of customers would enable organizations to plan for and improve customer engagement. In social CRM, customer referral value (CRV) and customer information (CIV) are also essential metrics of customer value along with customer lifetime value. Data mining techniques have been used to identify influential blogs, nodes, and opinion leaders that can be used to develop essential metrics for CRV and CIV. Successful implementation of social CRM would require seamless integration of social media data and data mining tools into CRM, not as an add on to CRM.

\section{References}

Baird, C.H., \&Parasnis, G. (2011). From social media to social customer relationship management. Strategy \& Leadership, 39(1), 30-37.

Brodie, R.J., Ilic, A., Juric, B., \&Hollebeek, L. (2013). Consumer engagement in a virtual brand community: An exploratory analysis. Journal of Business Research, 66(1), $105-114$.

Bijmolt, T.H.A., Leeflang, P.H., Bolok, F., Eisenbeiss, M., Hardie, B.G., Lemmens, A., \& Saffert, P. (2010). Analytics for customer engagement. Journal of Service Research, (13), 341-356.

Chettayar, K. (2002). Using customer information effectively. Financial Executive, 18(1), 42-43.

Deighton, J.A., \& Kornfeld, L. (2009). Interactivity's unanticipated consequences for marketers and marketing. Journal of Interactive Marketing, 23(1), 2 - 12.

Earnst, H., Hoyer, W.D., Kraft, M., \& Krieger, K. (2011). Customer relationship management and company performance - The mediating role of new product performance. Journal of the Academy of Marketing Science, $39(2), 290-306$.

Fan, Y.W. \& Ku, E. (2010). Customer focus, service process fit and customer relationship management profitability: The effect of knowledge sharing. The Services Industries Journal, 30(2), 203-223.

Finne, A., \&Gronroos, C. (2009), Rethinking marketing communication: From integrated marketing communications to relationship communication. Journal of Marketing Communications, 15(3), 179-195

Gummesson, E., \& Mele, C. (2010). Marketing as value co-creation through network interaction and resource integration. Journal of Business Market Management, 4(4), 181 - 198.

Greenberg, P. (2010). The impact of CRM 2.0 on customer insight. Journal of Business \& Industrial Marketing, 25(6), $410-419$.

Gronroos, C. (1994). From marketing mix to relationship marketing: Towards a paradigm shift in marketing. Management Decision, 32(2), 4 - 20.

Hansson, L., Wrangmo, A., \&Soilen, K.S. (2013). Optimal ways for companies to use Facebook as a marketing channel. Journal of Information, Communication, and Ethics in Society, 11(2), 112 - 126.

Hennig-Thurau, T., Malthouse, E.C., Friege, C., Gensler, S., Lobschat, L., Rangaswamy, A., \& Skiera, B. (2010). The impact of new media on customer relationships. Journal of Service Research, 13(3), $311-330$.

Jain, S.C. (2005). CRM shifts the paradigm. Journal of Strategic Marketing, 13(4), 275 - 291.

Jayachandran, S., Sharma, S., Kaufman, P., \& Raman, P. (2005). The role of relational information processes and technology use in customer relationship management. The Journal of Marketing, 69(4), 177-192. 
Kaplan, A.M., \&Haenlein, M. (2010). Users of the world unite! The challenge and opportunities of social media. Business Horizons, 53(1), $59-68$.

Kotler, P. (1992). Marketing's new paradigm: What's really happening out there. Planning Review, 20(5), 50 - 52.

Kumar, V., Akzoy, L., Donkers, B., Wiesel, T., Venkatesan, R., \&Tillmanns, S. (2010). Undervalued or overvalued customers: Capturing total customer engagement value. Journal of Service Research, 13(3), 297 - 310.

Labrecque, L., Jonas, E., Mathwick, C., Novak, T.P., \&Hofacker, C.F. (2013). Consumer power: Evolution in the digital age. Journal of Interactive Marketing, 27(4), 257 - 269.

Liu, H. \& Agarwal, N. (2009). Modeling and data mining in blogosphere. Synthesis Lectures on Data Mining and Knowledge Discovery. Volume 1

Madsen, D.O., \& Johnson, D. (2016). Examining customer relationship management from a management fashion perspective. Cogent Business \& Management, 3(1), $1-22$.

Malthouse, E.C., Haenlin, M., Skiera, B., Wege, B., \& Zhang, M. (2013). Managing customer relationship management in the social media era: Introducing the social CRM house. Journal of Interactive Marketing, 27(4), 270 - 280.

Mitic, M. \&Kapoulas, A. (2012). Understanding the role of social media in bank marketing. Marketing, Intelligence, \& Planning, 30(6), $668-686$.

Payne, A., \&Frow, P. (2005). A strategic framework for customer relationship management. The Journal of Marketing, 69(4), 167-176.

Peppers, D., Rogers, M., \& Dorf, B. (1999). Is your company ready for one-to-one marketing? Harvard Business Review, Jan - Feb 1999, 151 - 170

Rapp, A., Trainor, K.J., \& Agnihotri, R. (2010). Performance implications of customer-linking capabilities: Examining the complimentary role of customer orientation and CRM technology. Journal of Business Research, 63(11), $1229-1236$.

Reinartz, W., Manfred, K. \& Wayne, D.H. (2004). The customer relationship management process: Its measurement and impact on performance. Journal of Marketing Research, 41(3), 293 - 305.

Rigby, D.K., Reichheld, F.F. \& Schefter, P. (2002). Avoid the four perils of CRM. Harvard Business Review, Jan Feb. 2002, $101-109$.

Rygielski, C., et.al. (2002). Data mining techniques for customer relationship management. Technology in Society, 24(2), 483-502

Schulze, C., Skiera, B., \& Wiesel, T. (2012). Linking customer and financial metrics to shareholder value: The leverage effect in customer-based valuation. Journal of Marketing, 76(2), 17 - 32.

Shah, J.R., \& Murtaza, M.B. (2005). Effective customer relationship management through web services. Journal of Computer Information Systems, 46(1), 98 - 109.

Tinsley, B.D. (2002). Relationship marketing's strategic array. Business Horizons, 45(1), 70-77.

Thomke, S. \& Hippel, E.V. (2002). Customers as innovators: A new way to create value. Harvard Business Review, Mar-Apr 2002, 74-81.

Trainor, K.J. (2012). Relating social media technologies to performance: A capabilities-based perspective. Journal of Personal Selling and Sales Management, 32(3), 317 - 331.

West, J., (2001). Customer relationship management and you. IE Solution, April 2001, 34 - 37.

Yadav, R. \&Kharade, J. (2016). Survey of data mining tools and techniques for customer relationship management (CRM). International Journal for Research in Applied Science and Engineering, 4(1), 175 - 181. 